\title{
Force majeure and changed circumstances during the COVID-19 pandemic: the case of sports service contracts and judicial responses in China
}

\author{
Shuqi $\mathrm{Li}^{1} \cdot$ Peng $\mathrm{Nai}^{2} \cdot$ Guang Yang ${ }^{3} \cdot \mathrm{Tao}^{\mathrm{Yu}}{ }^{4}$
}

Accepted: 23 December 2021 / Published online: 20 January 2022

(c) T.M.C. Asser Instituut 2022

\begin{abstract}
This paper aims to explore the impact of COVID-19 on the performance of sports service contracts in China from a legal and judicial perspective. It attempts to contribute to the discussion on the applicability of the doctrines of force majeure and change of circumstances in the cases of impracticability of performance or obstructed performance due to COVID-19 and consequent government enforced pandemic control policies and measures. It reveals that courts in China have adopted a differentiated, pluralist, and practical approach according to the degree of the impact of COVID-19 preventive and control measures on the performance of contracts. The juridical responses by judges tend to favour the amendment of contract under the principle of changed circumstances with a view to balancing the interests of both parties to the contract and reducing the impact on the operations of the sport service industry. China's experience suggests that it is important that courts adhere to the principle of fairness, the principle of balance of interests, and the principle of encouraging transaction in dealing with contract performance disputes caused by COVID-19, while the applicability of force majeure should be carefully examined in judicial practice.
\end{abstract}

Keywords COVID-19 · Sports service contract · Force majeure $\cdot$ Change of circumstances $\cdot$ China

\section{Introduction}

The COVID-19 outbreak at the beginning of 2020 has become a major public health challenge in China and around the world (Jin et al. 2021; State Council Information Office 2020). On January 30, 2020, the World Health Organisation declared the COVID-19 outbreak a public health emergency of international concern. In order to contain the COVID-19

Tao $\mathrm{Yu}$

1299498248@qq.com

1 School of Sports Science, South China Normal University, Guangzhou, Guangdong Province, People's Republic of China

2 School of Law, Yunnan University of Finance and Economics, Kunming, Yunnan Province, People's Republic of China

3 Social Monitoring \& Research Division, Abu Dhabi Department of Community Development, Abu Dhabi, United Arab Emirates

4 Student Affairs Office, Yunnan Minzu University, Kunming, Yunnan Province, People's Republic of China pandemic, countries have taken various measures such as shutdown of businesses, home quarantine, social distancing, and suspension of large gathering activities, causing far-reaching social and economic implications (Evans 2020; Garcia-Garcia et al. 2020; Nicola et al. 2020). Government restrictions on travel, movement, and large gatherings have resulted in significant business interruptions and widespread event cancellations, with a particular impact on the sports services industry, which has seen the closure of stadiums, cancelation of sports events, suspension of physical fitness and training activities, as well as the stoppage of sports tourism (Nauright et al. 2020a). A large number of sports service contracts, consequently, have not been able to be perform normally, leading to numerous contract disputes (Wu et al. 2020).

A sports service contract is a type of service contract that takes sports services as the object of fulfilment. Sports services are commercial services provided by sports service providers to obtain economic benefits, including sports event services, sports training, fitness services, sports venue services, and sports sponsorship services. Same as other types of contracts, parties sign sports 
service contracts to safeguard their legitimate rights and interests and to ensure the normal conduct of the transaction. In general, if a party to a contract fails to fulfil its contractual obligations, it bears the liability for breach of the contract (Sun 2004).

However, it may not be fair to ask a party to continue to perform the contract when the occurrence of circumstances, such as government imposed epidemic or pandemic preventive guidelines, leads to the obstruction of contract performance. Although in some jurisdictions, sports service providers may be able to invoke force majeure provisions to excuse non-performance resulting from government pandemic containing measures, they do not always find their contracts containing a force majeure clause and have to resort to alternative law mechanisms for excuse of non-performance. In this case, it is important to understand how courts articulate force majeure and change of contractual circumstances in the light of the COVID-19 pandemic.

The legal ramifications of COVID-19 on a sports service business and its particular contractual obligations depend on the specific provisions of the contract and the particulars of the laws governing the interpretation and enforcement of the contract. An increasing number of studies have discussed force majeure and change of circumstances in the light of the COVID-19 pandemic (Alderman et al. 2020; Li 2020; Rospigliosi et al. 2020; Wang 2020; Yao and Que 2020). However, while many countries have established legal remedies to deal with changed contractual circumstances, the legal responses have been caught off guard by the large number of contract disputes that the COVID-19 pandemic has caused (Alderman et al. 2020). Improper relief for sports service contract disputes caused by COVID-19 could lead to the imbalance of interests of the contract parties and affect the resumption of work and operations of sports businesses.

This research approaches the impact of COVID-19 on the performance of sports service contracts in China from a legal and juridical perspective. It sets out to articulate several legal principles including force majeure, changed circumstances, and the common law doctrines of impossibility, impracticability and frustration of purpose, that contract parties should consider when evaluating how to address the difficulties of performance posed by the wide-ranging effects of COVID-19 and associated governmental regulations. It presents and discusses China's experience in judicial response to disputes over non-performance of sports service contracts due to COVID-19, as China is the first country to take strict COVID-19 preventive and control measures and has since accumulated experience in judicial practice. The discussion is also situated in a post-pandemic context, where the pandemic has been contained since the second half of 2020 and the attention has been shifted to the recovery strategy of the sports service industry (Wu et al. 2020).

\section{The impact of COVID-19 on the performance of sports service contracts}

The COVID-19 pandemic and the resulted government pandemic preventive and control policies and measures have impacted the ability of the sports service industry to maintain operations and fulfil contractual obligations. This is the fundamental reason why a large number of sports service contracts have not been performed normally. Therefore, it is necessary to first assess the scope and magnitude of the impact of COVID-19 on business operations of the sports service industry due to a combination of government regulations on large gatherings and contagion concerns.

The sudden outbreak of COVID-19 has affected the economies of almost all countries in the world, and the sports service industry is among the worst hit industries (Reade and Singleton 2020; Timpka 2020). The impact of government policy in enforcing COVID-19 preventive guidelines and health protocols on the sports service industry can be seen in the following several aspects. Firstly, while the provision of sports services depends on the supply of sports venues and personnel, many sports events and activities have been postponed, cancelled or held in other places, in order to prevent the spread of the pandemic (Barbosa et al. 2020; Nauright et al. 2020a; Sookaromdee and Wiwanitkit 2020). Statistics show that 18,970 sports events worldwide originally scheduled for April-August 2020 were postponed or cancelled (Balch 2020), including some major sports events such as European football leagues, 2020 World Team Table Tennis Championships, and 2020 Tokyo Olympic Games (Nauright et al. 2020b). The economic cost to the sports industry is huge, with an estimated \$61.6 billion missed revenues in 2020 (Balch 2020).

Secondly, the impact of COVID-19 has extended not only to sports events themselves, but also to sports sponsorship, sports advertising, sports venue leasing and other businesses downstream of the sports industry chain, which in turn caused losses to advertisers, sponsors and other commercial entities (Zhong et al. 2020). The sports service industry is the pillar industry of the sports industry in many countries, comprising mainly small businesses and grassroots sports entities, which are more vulnerable to movement restrictions and lockdown. The sports fitness and training industry, in particular, has been affected due to the closure of sports venues and has to adapt to new service delivery models. Many offline sports fitness and training activities have been suspended. Sports organisations have a number of characteristics that distinguish them from other service organisations and service 
quality matters a lot in maintaining customer loyalty in the sports sector (Ferrand et al. 2010; Robinson 2006). Although some fitness and training businesses have offered online services, it could only help maintain some existing customers (China News Network 2020a). Finally, due to the compulsory quarantine and traffic control measures, the sports tourism industry has been largely suspended, causing a staggering loss to the sports tourism industry (Escamilla-Fajardo et al. 2020). For example, the cancelation of the NCAA's March Madness games caused the fourth-round host Atlanta, Georgia to lose the contribution of 113,000 fans and 2,000 volunteers (Cooper and Alderman 2020).

In short, the COVID-19 pandemic has affected the global sports service industry to varying degrees, which have led to a large number of sports service contracts falling into nonperformance or facing enormous obstacles to perform (Balch 2020; Zhong et al. 2020). While sports service businesses should take proactive steps to ensure the continuity of their operations sufficient to meet existing contractual obligations as the COVID-19 pandemic continues to develop, proper and efficient legal and juridical response is required to settle contract disputes and to support the recovery of sports service industry.

\section{Force majeure and changed circumstances}

France first established force majeure as a modern legal doctrine, based on which Germany introduced the concept of impossibility of performance (Amkhan 1991; Baranauskas and Zapolskis 2009). Force majeure clauses excuse a party's non-performance under a contract when extraordinary events prevent a party from fulfilling its contractual obligations (Clark 2020). There is no doctrine of force majeure under common law, which is considered a creature of contract. Although the definition of force majeure has not been unified, many countries generally agree on the contract termination effect and exemption effect of force majeure but with different levels of flexibility (Baranauskas and Zapolskis 2009; Ye 2007).

Together with force majeure, changed circumstances in contracts are an important remedy system in modern contract law when discussing the obstacles of contract performance caused by objective circumstances (Hutchison 2010). To make up for the deficiency of the concept of impossibility of performance, the German court established the doctrine of changed circumstances. In 2002, all jurisdictions in Germany were prompted to re-examine their current approach to changed circumstances and conferred further flexibility on the judges to adapt the contractual terms to unexpected circumstances (Baranauskas and Zapolskis 2009). At present, civil law countries generally accept the legal effect of the change of circumstances on contract modification and contract termination (Rösler 2007; Ye 2007). However, these countries adopt a very cautious attitude towards the application of the doctrine of changed circumstances. For example, France does not provide for a regime of change of circumstances and explicitly refuses to grant relief even if unforeseen events have rendered contract performance undue burden (Wang and Zhang 2013).

As for the relationship between impossibility of performance and change of circumstances, German scholars believe that if a contract falls into the state of impossibility of performance, the obligations of the parties can be directly exempted without the need to apply the change of circumstances principle (Herresthal and $\mathrm{Xu}$ 2004). The common law system adheres to the principle of absolute liability in contract, and there is no provision for the change of circumstances principle. However, on the basis of force majeure and change of circumstances in civil law systems, the doctrine of frustration of contract was established in the common law system, which functions similarly to the principles of impracticability and impossibility. Additionally, compared with the effect of contract alteration and contract termination under the doctrine of changed circumstances, the principle of contract failure only establishes the effect of contract termination ( $\mathrm{Yu}$ 2017).

Whether COVID-19 and its effects constitute force majeure depends on several considerations. One important consideration is whether the performance of a contract is merely impracticable or truly impossible as the result of pandemic preventive and control regulations. In some jurisdictions, contract parties may excuse non-performance through availing themselves of the common law doctrines of impossibility and impracticability.

\subsection{Impossibility of performance}

Impossibility of performance (or frustration of contract) means that a contract cannot be performed due to a change in circumstances and the parties could not have foreseen and mitigated the potential non-performance. The occurrence of COVID-19 and the subsequent enforcement of government pandemic preventive and control guidelines is an objective event and is not under the control of the contract parties. Impossibility of performance can be further categorised into original impossibility and subsequent impossibility, subjective impossibility and objective impossibility, and temporary impossibility and permanent impossibility (Feng 2003).

Given that the COVID-19 pandemic and the associated preventive regulations are temporary in nature and most sports activities are expected to gradually return to normal, the non-performance of sports service contracts can be considered as temporary failure. Nevertheless, permanent impossibility of performance does occur. For example, a 
service contract is formed between an organiser of a sports event and the audience through the sale and purchase of tickets. If the event is cancelled due to COVID-19, the organiser will be in a situation where the contract cannot be fulfilled permanently.

\subsection{Impracticability of performance or unduly burdensome to perform}

Impracticability or unduly burdensome to perform means that although the contract can continue to be performed after an unforeseen event occurs, the equilibrium of a contract has fundamentally altered resulting in an excessive burden being placed on one of the parties involved, and the continued performance of the contract becomes unfair or unreasonable to one party or fails to achieve the original purpose of the contract. This is also known as the hardship clauses in contract law, which typically recognise that parties must perform their contractual obligations even if events have rendered performance more burdensome than would have been anticipated at the time of the conclusion of the contract (Rösler 2007). However, if continued performance has become excessively burdensome, the parties are obligated to negotiate alternative contractual terms to allow for the consequences of the event reasonably distributed between the parties. Different legal systems tend to have different interpretations. In Germany, for example, unduly burdensome to perform means difficulty beyond obligation (Wang and Chang 2013).

While COVID-19 has brought impossibility of performance to most sports service contracts, it has also led to impracticability of performance or unduly burdensome to perform to some sports service contracts (Zhong et al. 2020). Due to the closure of stadiums and gymnasiums, many sports training businesses cannot carry out offline services normally, resulting in the failure of sports training institutions to fulfil their contractual obligations. The closure of the stadiums and training venues as such does not make it impossible for the sports training institutions to continue to fulfil the sports venue rental contracts signed with sports venue providers, but it does make it economically difficult for sports training businesses to continue the rental contracts. It may be unfair for sports training institutions to continue to pay rent according to the original agreement.

It should be noted that whether the impact of COVID19 on the performance of a sports service contract leads to impossibility or impracticability of performance, it may cause losses to the parties to the contract, and in this case the parties cannot be forced to continue to perform the contract in accordance with the original agreement. Two issues may arise: the first is how to remedy contracts that fall into nonperformance; the second is the issue of exemption due to the impact of the pandemic.
The legal rule of force majeure or impossibility has traditionally been criticised for the high threshold for invoking it (Burrows 2015; Hutchison 2010). For COVID-19-related cases, this will often not be a barrier as legislation enforcing lockdowns has made many contracts impossible or unduly burdensome to perform. Potentially, it may be an issue in cases of obstructed contract performance such as a contract being suspended for only part of its duration. In addition, in most legal systems such rules also tend to fail to take adequate account of events that impact on the party's ability to perform the contract (Li 2001; Peng 2014).

In China's legal scholarship, there are different views on the nature of contract performance barriers caused by COVID-19 and on the application of laws involving force majeure and changed circumstances in the judicial relief for the burden on a party's ability to perform the contract caused by COVID-19-induced change of circumstances. Some scholars argue that the nature of impracticability of performance caused by COVID-19 may be deemed as either force majeure or changed circumstances, depending on the specific circumstances of the case (Fan 2020; Tan and Gong 2002; Yao and Que 2020). In judicial practice, if a contract cannot be performed due to the impact of government epidemic/pandemic preventive measures, it shall be deemed as force majeure. If the performance of a contract only becomes difficult, it should be deemed as change in circumstances (Fan 2020). Such a view has been questioned for several reasons. First of all, from the perspective of legal doctrine, the legal nature of COVID-19-related contractual performance barriers cannot be regarded as both force majeure and changed circumstances. It should be determined based on objective assessment of constitutive elements of force majeure, rather than subjective assessment of whether the contract can continue to be performed (Wang 2020). Secondly, the occurrence of force majeure is the cause of failure to perform the contract, and it is inappropriate to judge the cause by referring to the result. Therefore, some Chinese legal analysts argue that while by nature the impact of COVID-19 preventive and control policies and measures should be considered as force majeure, the doctrine of changed circumstances or the principle of fairness should also be applied by analogy (Yao and Que 2020).

Thus, there are two main approaches in China's legal scholarship to the determination of the nature of contract non-performance or performance barriers posed by COVID19: one is based on the consequences of the pandemic preventive and control measures, and the other is based on the constitutive elements of force majeure (Tan and Gong 2002). Although there are differences in the two approaches, the idea of applying the doctrine of changed contractual circumstances is the same. It is a matter of whether COVID-19-related changes are applied directly as the doctrine of changed 
circumstances or by analogy, or the doctrine of changed circumstances is applied with the principle of fairness.

This research supports the approach that places the nature of COVID-19 preventive and control measures, rather than the impact on contract performance, as the basis for determining the obstacles to contract performance. It should be noted that in the case of force majeure exemption provisions, the doctrine of changed circumstances can still be applied in judicial practice. However, the authors do not agree with the analogy application of the doctrine of changed circumstances. How to understand the relationship between force majeure and changed circumstances will be discussed in detail in China's legal provisions and juridical practice.

\section{China's experience}

One of the important implications of a global pandemic is that it can expose the inadequacies of the legal system and prompt us to reflect on the shortcomings of the current legal system (Yao 2008). In the context of China, the Legal Affairs Commission of the People's Republic of China recognised the nature of the COVID-19 pandemic preventive and control measures as force majeure (China News Network 2020b). However, the Commission did not define and explain the situations that fall under the category of impracticability of performance.

\subsection{China's legal remedy system}

As for the legal remedy system for obstructed contract performance caused by the occurrence of objective circumstances, China has drawn lessons from the force majeure doctrine and the change of circumstances doctrine in the civil law system, as well as the contract failure principles in the common law system, and formed a unique legal system. The Contract Law of the People's Republic of China (hereinafter referred to as the "Contract Law") and the General Principles of the Civil Law of the People's Republic of China both define force majeure as "unforeseeable, unavoidable and insurmountable objective circumstances". Article 94 and Article 117 of the Contract Law clearly stipulate

\footnotetext{
1 The first paragraph of Article 94 of the Contract Law stipulates: "If the purpose of the contract cannot be realised due to force majeure, the parties may terminate the contract".

${ }^{2}$ Article 117 of the Contract Law stipulates: "if a contract cannot be performed due to force majeure, it shall be exempted from liability in part or in whole according to the impact of force majeure. If force majeure occurs after the party's delay in performance, it cannot be exempted from liability".

3 Article 118 of the Contract Law stipulates: "if a party is unable to perform the contract due to force majeure, it shall timely notify the
}

the force majeure contract termination effect ${ }^{1}$ and exemption effect respectively ${ }^{2}$. Article 118 of the Contract Law also stipulates the notification and proof obligations of the parties. $^{3}$

Before the promulgation of the Civil Code of the People's Republic of China (hereinafter referred to as the "Civil Code"), there was no explicit provision on change of circumstances in China's legislation. The principle of changed circumstances was once proposed in the Contract Law (draft), but it was not finally adopted. The reason was that since force majeure had been stipulated in the Contract Law, it may be superfluous to stipulate the change of circumstances principle. More importantly, there was a concern over potential abuse of the principle of changed circumstances when an immature article was adopted (Wang 2019).

After the Wenchuan earthquake in 2009, the Supreme People's Court of China (hereinafter referred to as the "Supreme People's Court") stipulated the principle of changed circumstances in Article 26 of Interpretation of the Contract Law II, in order to meet the needs of judicial practice. ${ }^{4}$ This article specifies the effect of amending and terminating a contract under changed contractual circumstances. However, it clearly stipulates that change of circumstances is caused by "non-force majeure", thus excluding force majeure from the causes that lead to change of circumstances. Legislators were inclined to use the force majeure doctrine to solve disputes of contractual non-performance caused by unforeseeable and unavoidable changes of objective circumstances. Thus, a distinctive dual normative system had been established in Chinese legislation between the force majeure and the changed circumstances principles (Han 2014; Li 2020).

\subsection{Application of force majeure and change of circumstances in judicial practice}

Before the promulgation of the Civil Code, although Chinese legislators perceived the relationship between force majeure and change of circumstances mutually exclusive, the judicial

Footnote 3 (continued)

other party in order to mitigate the losses that may be caused to the other party, and shall provide proof within a reasonable time limit".

4 The doctrine of change of circumstances is stipulated in Article 26 of Interpretation of the Contract Law II. "After the signing of the contract, when the changes of objective contractual circumstances do not fall under the change of business risks that are unforeseen by the parties in the contract and caused by non-force majeure, and when continuing to perform the contract causes obvious unfairness to one party or cannot realise the purpose of the contract, and when one party requests the People's Court for contract amendment or rescission, the People's Court shall, according to the principle of fairness and based on the actual situation of the case, determine whether the contract should be amended or rescinded." 
practice often contradicted to the relevant legislative provisions. When dealing with disputes of obstructed contract performance caused by objective circumstances, courts recognised that COVID-19 constitutes a force majeure event, but often looked to examine whether the performance of the contract is merely economically difficult or truly impossible. Judges tended to liberalise the force majeure principle to account for market realities and prefer contract modification under the principle of changed circumstances to promote the continued performance of the contract ( $\mathrm{Li} 2020)$. The application of these judicial practices was evident during the SARS epidemic and the COVID-19 pandemic.

In handling with contract performance disputes after the outbreak of SARS in 2003, which was considered as qualifying for force majeure, the fairness principle was generally applied in the judicial judgment with a view to modifying the contracts. Out of the 37 cases filed by the parties concerning force majeure during the SARS epidemic, 27 of them were supported by the court confirming the application of the force majeure doctrine, among which 18 cases confirmed the exemption effect of force majeure and the other 9 cases regarded force majeure as the reason of contract modification (Li 2020). Considering that in 2003 the law did not explicitly stipulate the doctrine of changed circumstances, if the courts ruled in favour of contract modifications in light of the principle of fairness, it would be the juridical application of the principle of changed circumstances in contract law in China.

There was some confusion and crossover in the application of force majeure and change of circumstances in Chinese judicial practice during the SARS epidemic, which was contrary to the parallel relationship between force majeure and change of circumstances as stipulated in the legislation. The premise of claiming a force majeure is that the occurrence of objective circumstances leads to the impossibility of performance of a contract. There are legal loopholes for the impracticability of performance or unduly burdensome to perform situation of contract performance caused by the occurrence of objective circumstances that is qualified as force majeure. In practice, courts in China are more inclined to apply the change of circumstances doctrine to fill the legal gap and have done it in different ways. The practice in judicial practice reveals that a clear and distinct relationship between force majeure and change of circumstances needs to be stipulated in Chinese legislation.

\subsection{The civil code}

The recently promulgated Civil Code responds to the legal loopholes between force majeure and changed circumstances in legislation and practice. It not only explicitly establishes the principle of changed circumstances, but also makes two modifications compared with Interpretation of the
Contract Law II: one is to delete the expression of "nonforce majeure" in Interpretation of the Contract Law II; the other is to stipulate renegotiation obligations of the parties to the contract. The deletion of "non-force majeure" means that in the Civil Code the parallel relationship between force majeure and changed circumstances has been eliminated and that force majeure can be considered as the cause of changed circumstances, establishing a causal relationship between force majeure and changed circumstances (Wang 2020). The Civil Code thus bridges the gap in the legislation, explaining that the occurrence of force majeure events leads to the difficulty of contract performance. The causal relationship between force majeure and changed circumstances established by the Civil Code appears to be more convincing, compared with the analogy approach proposed by scholars that applies the principle of changed circumstances and the principle of fairness to contract amendments.

\subsection{China's judicial response to COVID-19-related cases}

With the rapid development of China's fitness service industry, the number of contract performance disputes has increased. A search on pkulaw.com, the legal database of Peking University showed that there were 25,864 fitness service contract dispute adjudication documents as of December 17, 2020, and the number of adjudication documents in recent years was as high as 5,264. The COVID-19 pandemic preventive and control measures adopted at the beginning of 2020 have incurred heavy losses on the fitness industry and tended to produce group disputes.

Specifically for the empirical cases analysed by this research, we searched relevant cases on China Judgements Online $^{5}$ maintained by the Supreme People's Court using the combination of keywords-'contract', 'sports', 'epidemic', and 'resumption of work and production'. The principle of selecting only one of the cases of a same defendant was followed. After excluding irrelevant cases, 69 cases were further screened, sorted out, and analysed. The judgement date of these 69 cases was all after the outbreak of COVID19 in 2020.

\subsubsection{Case categories}

There are different types of sport service contracts such as fitness service contracts, sport sponsorship contracts, and sport venue service contracts. As shown in Table 1, the largest number of disputes resulted from the impact of the

\footnotetext{
5 The Supreme People's Court of China. China Judgements Online. Available: https://wenshu.court.gov.cn. Accessed on 20 September 2021.
} 
Table 1 Case types

\begin{tabular}{lll}
\hline Case type & Number & Percentage \% \\
\hline Sports training service contract disputes & 13 & 18.8 \\
Fitness service contract disputes & 26 & 37.7 \\
Sports venue lease contract disputes & 18 & 26.1 \\
Sports tourism contract disputes & 4 & 5.8 \\
Sports sponsorship contract disputes & 1 & 1.4 \\
Other & 7 & 10.1 \\
\hline
\end{tabular}

Table 2 Types of legal document

\begin{tabular}{llc}
\hline Types of legal document & Number & Percentage \% \\
\hline Mediation statement & 5 & 7.2 \\
Judgment & 64 & 92.8 \\
\hline
\end{tabular}

pandemic are fitness service contract disputes (37.7\%), followed by sports venue leasing contract disputes $(26.1 \%)$ and sports training service contract disputes (18.8\%). The number of contract disputes of these three types accounts for more than $80 \%$ of the total cases. It is clear that most of these disputes are directly related to the fitness service industry and training service industry, which are comprised of mainly small and medium-sized enterprises. In the face of the huge impact of the pandemic, small- and medium-sized enterprises are more likely to have financial problems and face difficulties to continue to operate, resulting in obstacles to the performance of signed contracts and consequently a large number of disputes.

\subsubsection{Resolution of cases}

When it comes to dispute resolution, only five of the 69 cases were settled by mediation (Table 2), out of which four cases were selected and announced by the Supreme People's Court as typical guiding cases. The dispute resolution methods of these four cases were in line with the Guidance of the Supreme People's Court on Several Issues Concerning the Proper Trial of Civil Cases Involving COVID-19 (I), which states that "priority should be given to mediation, and parties should be actively guided to negotiate and reconcile, share risks and overcome difficulties together". It indicates that in the face of the impact of the pandemic, the Supreme People's Court has attached great importance to the use of mediation to resolve disputes with a view to helping smalland medium-sized enterprises resume work and production.

For example, one of the typical cases issued by the Supreme People's Court to guarantee the resumption of work and production during the pandemic period was related to a fitness club lease contract dispute in Zhejiang province. The fitness club was closed due to the COVID-19 pandemic and was unable to pay the rent to a real estate company in Yuhang city, Hangzhou. The real estate company appealed to court to terminate the contract. The court took into consideration that the fitness club had a good reputation and that it would not be able to resume normal work and operations if the contract was terminated, and mediated between the two parties and the real estate company agreed to postpone the rent payment. At present, the fitness club has been operating normally and the rights and interests of both parties and club members have been guaranteed.

The guiding cases issued by the Supreme People's Court have provided guidance for provincial and local courts to handle similar cases. Also in Zhejiang, the Zhejiang Province Higher People's Court released "Zhu and Others with X Fitness Company and its Subsidiary Company in Tongxiang Contract Dispute" case. Because the fitness company did not operate in accordance with the contract and fulfil its refund commitment after recruiting members, on May 27, 2020, 257 members jointed acted as plaintiffs and appealed to the court against the fitness company. To protect the rights and interests of the members, as well as to facilitate the resumption of operations of the fitness company, the judge adopted the mediation approach after investigating the situation and resolved the dispute in time.

\subsubsection{Identification of the nature of pandemic prevention and control measures}

A review of similar cases indicates that the contract performance disputes during the pandemic mainly centre on contract termination and distribution of losses caused by COVID-19. In judicial practice, courts generally hold that the nature of COVID-19 preventive and control measures should be recognised as force majeure and directly indicate in the judgment. For example, in the case of "Lease Contract Dispute between Zhang Weiwu and Shanghai Maisen Sports Event Planning Co., Ltd", the judge directly indicated that the COVID-19 pandemic is force majeure. In some cases, although judges did not directly identify the nature of the COVID-19 pandemic as force majeure in their judgment, the provisions of paragraph 1 of Article 94 of the Contract Law were applied in the final judgment, indirectly indicating that the nature of the COVID-19 pandemic is force majeure.

\subsubsection{Chinese court's judgment on contract termination}

As for the rescission of a contract, if both parties reach an agreement on the cancelation of the contract, the court will support the parties' autonomy of the contract and terminate the contract. If there is no agreement, judges will consider several factors including mainly whether the purpose of the contract can be achieved given the impact of the pandemic. As shown in Table 3, in some cases when the judge believed 
Table 3 Circumstances of contract termination due to epidemic factors

\begin{tabular}{|c|c|c|}
\hline Case number & Judge' judgement & Final verdict \\
\hline (2020) Yu 0503 Min Chu No. 3661 & $\begin{array}{l}\text { The defendant is now out of business, which makes the plaintiff unable to } \\
\text { achieve the purpose of the contract }\end{array}$ & Contract terminated \\
\hline (2020) Jing 0115 Min Chu No. 19433 & $\begin{array}{l}\text { It was not opened after the epidemic, thus the plaintiff could not achieve the } \\
\text { purpose of the contract }\end{array}$ & Contract terminated \\
\hline (2021) Liao 0402 Min Chu No. 375 & $\begin{array}{l}\text { The plaintiff' contract purpose could not be realised due to no business after the } \\
\text { epidemic }\end{array}$ & Contract terminated \\
\hline (2020) Jing 0116 Min Chu No. 2848 & Changing the training period cannot achieve the purpose of the contract & Contract terminated \\
\hline (2021) E 0103 Min Chu No. 668 & $\begin{array}{l}\text { The defendant closed down the business, thus the plaintiff could not achieve the } \\
\text { purpose of the contract }\end{array}$ & Contract terminated \\
\hline (2021) Jing 02 Min Zhong No. 5405 & The epidemic does not necessarily make the purpose of the contract impossible & Plaintiff' claim rejected \\
\hline (2021) Jing 0101 Min Chu No. 5911 & $\begin{array}{l}\text { The impact of the epidemic did not make the purpose of the lease contract } \\
\text { impossible to achieve }\end{array}$ & Discharge of \\
\hline \multicolumn{3}{|l|}{ contract by breach } \\
\hline (2021) Jing 02 Min Zhong No. 9401 & $\begin{array}{l}\text { The epidemic situation does not make the contract impossible to continue to } \\
\text { perform }\end{array}$ & Plaintiff' claim rejected \\
\hline (2021) Liao 1282 Min Chu No. 2254 & $\begin{array}{l}\text { The defendant closed down for several months, so that the plaintiff could not } \\
\text { achieve the purpose of the contract }\end{array}$ & Contract terminated \\
\hline (2021) E 0192 Min Chu No. 689 & The plaintiff' purpose of the contract can still be achieved & Plaintiff' claim rejected \\
\hline (2020) Liao 0211 Min Chu No. 8503 & Should continue to perform and negotiate on how to change the contract & Plaintiff' claim rejected \\
\hline
\end{tabular}

that the purpose of the contract cannot be achieved due to the impact of epidemic prevention and control, the judge would decide to terminate the contract. The purpose of the contract cannot be achieved mostly under the circumstances where the business is no longer operating due to the impact of COVID-19. For example, in the case of "Service Contract Dispute between Zhang Wei and Wuhan Aikesi Sports Development Co., Ltd.", the judge held that the plaintiff could not use the swimming \& gym facilities since January 1,2020 , due to the closure of the defendant, and thus the plaintiff could not achieve the purpose of the contract and finally ruled that both parties should terminate the contract. Conversely, if the judge determined that the purpose of the contract can still be achieved and it can continue to perform through changing the contract, the judge would reject the plaintiff's request to terminate the contract. Referring to the guidance issued by the Supreme People's Court, judges were more inclined to encourage contract parties to continue their transactions by changing the contract unless the purpose of the contract cannot be realised due to the impact of pandemic.

Another case examined here is a sport sponsorship contract dispute. Although sports sponsorship contract disputes account for a very small percentage of the cases on China Judgements Online, with the increasing number of sport events held in China in recent years, sport sponsorship contracts have increasingly become a focus of Chinese legal scholars (Wu et al. 2020). The outbreak of COVID-19 caused many sports events to be disrupted and controversies over sport sponsorship contracts to increase.
Sport sponsorship contract disputes mainly focus on how to distribute the losses caused by the cancelation of sport events and whether the contract can be rescinded. For example, in the case of "Contract Dispute between Alxa League Shasai Sports Industry Co., Ltd. and Xilinmen Furniture Co., Ltd.”, Shasai Sports signed a sponsorship contract with Xilinmen. Due to COVID-19, five events were cancelled. In order to continue to perform the contract, Shasai unilaterally changed the May $1^{\text {st }}$ Asian games to be held online. Xilinmen believed that hosting an online event would not serve well as a pre-promotional function, so it stopped paying the agreed sponsorship fees. Shasai Sports thus appealed to court to demand the sponsorship fees. The court of first instance held that the outbreak of COVID-19 meant that the parties were unable to continue the contract and it should be deemed as force majeure. Thus, both parties shall be exempted from the liability for breach of contract, and the contract shall be terminated as the purpose of the contract cannot be realised. However, due to the consideration of maintaining stable trade order, forced termination of the contract was not temporarily granted. The court of the second instance held that for Xilinmen the purpose of the contract could no longer be achieved and the contract should be terminated. However, Xilinmen should compensate Shasai 200,000 yuan for the online publicity that Shasai had done. The judicial experience of this case suggests that whether a sport sponsorship contract can be rescinded in the light of COVID-19 impact depends on whether the purpose of the contract can be realised. 


\subsubsection{Determination of liability for breach of contract}

As for the determination of liability for breach of contract, the judge would first consider the time of the introduction of COVID-19 prevention and control measures and whether there is a causal relationship between pandemic prevention and control and obstacles to contract performance. In the case of "Contract Dispute between Beijing Sports Competition Management Center and Dongbaite (Beijing) Sports Development Co., Ltd.", the judge held that the breach of contract occurred before the pandemic, therefore there was no causal relationship between the occurrence of the pandemic and the failure of the defendant to perform its contractual obligations; therefore, the defendant's defence was not taken.

Judging from the sample cases involving liability for breach of contract, in most cases judges tended to exempt all liability based on the recognition of the COVID-19 pandemic as force majeure. In a typical case of a travel contract dispute due to the postponement of Tokyo Olympics issued by the Chengdu Intermediate People's Court, the judge informed the plaintiff that the defendant had terminated the contract due to force majeure and did not involve accountability for breach of contract.

However, in some cases, the judge would determine the amount of liquidated damage based on the principle of fairness, the degree of impact of the pandemic on the performance of the contract, and the degree of fault of both parties. For example, in the case of "Mo Yunhai and the Beihai Expeditionary Fitness Club Lease Contract Dispute", the two parties agreed that they could not use the stadium during the pandemic, but both parties violated the agreement. After investigating the facts, the court determined that the actions of both parties had de facto reached an agreement to terminate the contract, thus decided to terminate the contract and distributed the losses of the parties according to the principle of fairness. For the loss suffered by the party who purchased the fitness service, the count would generally ask the party providing the fitness service to make up for it, even if the contract has a force majeure exemption clause. This was illustrated in the case of "Gong Minjie and Wuhan Jinyejian Fitness Investment Management Company". Due to the impact of COVID-19, Jinyejian fitness company could not operate normally and perform the contract. Although there was a force majeure exemption clause between the two parties, the court ruled that Jinyejian fitness company should make up for it by extending the contract duration.

\section{Discussion and recommendations}

To manage disputes of sports service contract performance caused by COVID-19 preventive and control measures, it is necessary to combine the existing legal relief principle with the concrete cases in the juridical practice with a view to achieving an equilibrium of a contract between the parties, stabilising the social order, and facilitating the resumption of work and operations of sports businesses. This research calls on courts in China to pay attention to the following aspects when dealing with disputes over non- or delayed performance of sports service contracts caused by government COVID-19 preventive and control measures.

\subsection{The guiding principles}

Legal principles have a guiding role in the application of the legal system and a substantial impact on the rights and obligations of the parties to a contract. Combined with China's judicial experience, it is suggested that the following three principles should be adhered to in dealing with sports service contracts that are impractical to perform or unduly burdensome to perform.

The first principle to follow is to encourage and promote transactions, which is the purpose of modern contract law. When and where a contract can continue to be performed and the purpose of the contract can be realised despite the impact of COVID-19, the parties to the contract shall be encouraged to continue to perform. A party who can continue to perform but refuses to perform shall be liable for breach of contract. If COVID-19 has resulted in undue burden on one of the parties and the continued performance of the contract becomes unfair to the party, the parties concerned should be actively guided to negotiate contractual terms to allow the continued performance of the contract. If the purpose of the contract cannot be realised, the litigant's request for termination of the contract should be supported.

In the judicial relief for obstructed performance of sports service contracts caused by COVID-19, the application of force majeure and changed circumstances should be considered to determine whether a fair legal effect can be produced between parties. To adhere to the principle of fairness and justice, the termination of contract and exemption of the parties by invoking force majeure should be carefully handled. Additionally, if the parties request the court to change or revoke the contract, a mediation or remedial approach should be adopted under the principle of fairness through examining and reviewing the contents of the contract, the development of the pandemic, and the degree of impact of the pandemic on the performance of the contract.

If a sports service contract cannot be performed normally and this has caused a loss for the parties, the principle of balance of interests should be applied. In the trial of specific cases, judges need to protect the legitimate rights and interests of all parties equally according to law and handle disputes effectively by upholding the principles of mediation, consultation and mutual understanding, sharing risks and overcoming difficulties together. 


\subsection{Specific juridical strategies}

The guiding cases issued by China's Supreme Court illustrate that some COVID-19-related contract disputes are not resolved in accordance with the strict application of the law, but in accordance with the mediation process. The main function of mediation is to avoid the inflexibility and prejudice that are inherent to the application of law to resolve disputes (Li 2001). Mediation helps better balance the interests of the parties through consultation and negotiation, and it is more efficient and economical than court ruling (Zhang 2014). The guiding cases show that given the large number of COVID-19-related sports service contract disputes, mediation as a useful and effective tool could quickly resolve disputes, facilitate the resumption of operations of sports businesses, and promote social harmony and industrial development.

As both force majeure and change of circumstances are the exceptions to the principle of strict observance of contract, their applicability in judicial practice should be carefully examined. First, epidemic/pandemic control measures must occur after the conclusion of the contract and before the completion of performance. If a contract is signed by the parties after the outbreak of COVID-19, the unpredictability of the occurrence of force majeure events cannot be satisfied. If a party delays the performance of the contract and the COVID-19 pandemic preventive and control measures take place, the party's claim of force majeure exemption shall not be supported. Second, the party claiming the application of force majeure or change of circumstances must provide proof that the loss was directly caused by the government imposed pandemic control measures. Therefore, the court should focus on examining the causal relationship between COVID-19 preventive and control measures and the obstructed performance of contracts. Only after confirming that COVID-19 preventive and control measures are the fundamental, direct, and key cause for the obstructed or non-performance of a sports service contract, can the legal effect of applying force majeure or changed circumstances be accepted. Finally, the degree of the impact of pandemic control measures on the performance of sports service contracts is different, and the application of laws involved may also be different. The application of force majeure and the change of circumstances should be confirmed according to the specific situation where the pandemic control measures led to impossibility or impracticability of performance.

Encouraging and facilitating the resumption of operations of sports businesses should be highlighted and the contract parties shall be actively guided to amend or recompose the contract. As mentioned above, the sports service industry has suffered enormously from COVID-19 and many sports businesses face huge obstacles to resume normal operations. If a sports service contract cannot be performed due to COVID-19, courts shall comprehensively consider the main purpose of the contract signed by the affected parties. In addition to the cases in China analysed above, a similar judicial response is also demonstrated in the case of Olg Bremen NJW 1953, 1393, concerning sports venue leasing in Germany. ${ }^{6}$ Despite the burden on contract performance posed COVID-19, if a sports service contract could be continued to perform to achieve the purpose of the contract, the parties should be encouraged to continue to perform or change the contract terms, rather than to terminate the contract. The "one size fits all" approach should be avoided. China's experience shows how contract disputes could be handled when COVID-19 has caused impracticability of performance or undue burden to perform for many sports service contracts.

China's legal system affirms the causal relationship between force majeure and the change of circumstances in response to the need for judicial practice. Although the nature of the COVID-19 pandemic preventive and control measures are identified as force majeure, the doctrine of changed circumstances can still be applied to contracts with obstructed performance. Compared to contract termination, changing the contract is more conducive to maintaining the existing transaction and alleviating the impact of the pandemic on sports enterprises. Therefore, in the trial of relevant cases, courts should actively guide the parties to change the contract and provide incentives for the parties to reach cooperative solutions (Alderman et al. 2020).

It is worth mentioning that exemption does not mean that all liability should be exempted. For the loss of one party, if the debtor claims exemption citing the impact of COVID19 as an excuse, courts shall not accept that and rule that the debtor shall be exempted from all liabilities even when the COVID-19 pandemic preventive and control measures are recognised as force majeure. The debtor's exemption scope should be determined based on the impact of the pandemic control measures on the contract. In the event that the entire sports service contract cannot be performed due to COVID-19 and if the parties plead force majeure, the court shall determine that the debtor be exempted from liability. If COVID-19 control measures are only part of the cause for the non-performance or only cause the failure to perform part of the contract, the debtor shall be partially exempted

\footnotetext{
${ }^{6}$ In this case, the plaintiff and the defendant entered into a sports venue lease contract with the stadium as the venue for the performance and paid the defendant a rent of 1,500 marks. However, when the plaintiff fell ill and the show was cancelled, the plaintiff demanded the return of the rent. The Bremen Court of Appeal held that the plaintiff had rented the space for a performance, and that the specific purpose of the performance had become known to the defendant, and that the purpose of the performance had become the basis for the transaction of the lease. In the end, the court upheld the plaintiff's claim that the defendant should return the money.
} 
from liability according to the principle of proportionate liability. If COVID-19 makes the performance of a contract unreasonably difficult and the party applies for exemption of liability on the basis of changed circumstances, the court shall, in accordance with the principle of fairness, order both parties to reasonably share the loss or one party to compensate part of the loss incurred to the other party.

Renegotiation obligations assists in overcoming the rigidity of contract (Wang 2019). In the disputes of obstructed performance of sports service contracts caused by COVID19 , strengthening the renegotiation obligations of the parties involved is a manifestation of respecting the autonomy of will of the parties, which is beneficial for honest negotiations between the parties. Through negotiations, the two parties are encouraged to reach a new agreement to change the existing transactions, so as to realise the legislative purpose of encouraging transaction of the Contract Law.

The cases summarised and analysed in this paper took place before the implementation of the Civil Code, when courts in China did not emphasise renegotiation obligations of the contract parties when dealing with disputes over the performance of sports service contracts. The Civil Code has added relevant provisions on renegotiation obligations of the contract parties under the principle of changed circumstances. According to the Civil Code, if the parties to a contract do not actively perform renegotiation obligations, they should bear the adverse consequences for not performing their obligations. Renegotiation obligations has not been incorporated into many legal systems in the world; therefore, internationally it may not be a legal obligation of all parties to a contract to perform it (Zhang and Ning 2019). Many civil law systems, however, tend to follow the principle of good faith to impose a duty to renegotiate in extraordinary circumstances. This is what the Civil Code of China has done. The guiding cases issued by the Supreme People's Court provide necessary guidance as to what renegotiated contract terms may be imposed in response to COVID-19-induced change of circumstances.

\section{Conclusion}

The COVID-19 outbreak in early 2020 has had a huge impact on China's sports service industry, causing a large number of sports service contracts to fall into non- or obstructed performance. The review of this paper shows that China's judicial response to public emergencies has gone through a process from contradiction between written legislation and judicial practice to coordination between theoretical interpretation and judicial practice, and finally to confirmation of theoretical research results through legislation. Its purpose is to achieve fairness, balanced interests between parties, and the judicial effect of promoting the continuation of transactions.
In the face of the impact of COVID-19 on the sports service industry, China's swift and sensitive judicial response has set up an example of coping with the implications of the pandemic through a pluralist and flexible approach with a view to assisting the recovery of the sports service industry, and ultimately striving to maintain social stability, order and harmony.

Funding Not applicable

\section{Declarations}

Conflict of interest No potential conflict of interest was reported by the authors.

\section{References}

Alderman R, De Franceschi A, Giancaspro M, Howells G, Lei C, Lete J, Micklitz H-W et al (2020) Consumer law and policy relating to change of circumstances due to the COVID-19 pandemic. J Consum Policy 43(3):437-450

Amkhan A (1991) Force majeure and impossibility of performance in Arab contract law. Arab Law Q 6(3):297-308

Balch G (2020) COVID-19 and sports's new world order. Two Circles. https://twocircles.com/gb-en/articles/ sports-new-world-order/

Baranauskas E, Zapolskis P (2009) The effect of change in circumstances on the performance of contract. Jurisprudence 4(118): 197-216

Barbosa BT, De Lima-Junior D, Da Silva Filho EM (2020) The impact of COVID-19 on sportsing events and high-performance athletes. J. Sp Med Phys Fit 60(11):1507-1508

Burrows A (2015) Principles of the English law of obligations. Oxford University Press, Oxford

China News Network (2020b) The National People's Congress Standing Committee: Inability to fulfill the contract due to epidemic prevention and control falls into force majeure. http://www.china news.com/m/gn/2020/02-10/9086203.shtml?ivk_sa=1023197a (in Chinese)

Clark JR (2020) Can I get a force majeure from a novel coronavirus? Air Med J 39(4):235-236. https://doi.org/10.1016/j.amj.2020.04. 019

Cooper JA, Alderman DH (2020) Cancelling march madness exposes opportunities for a more sustainable sports tourism economy. Tour Geogr 22(3):525-535

Escamilla-Fajardo P, Nunez-Pomar JM, Calabuig-Moreno F, GomezTafalla AM (2020) Effects of the COVID-19 pandemic on sports entrepreneurship. Sustainability 12:8493. https://doi.org/10.3390/ su 12208493

Evans AB, Blackwell J, Dolan P, Fahlén J, Hoekman R, Lenneis V, McNarry G, Smith M, Wilcock L (2020) sports in the face of the COVID-19 pandemic: towards an agenda for research in the sociology of sports. Eur J Sp Soc 17(2):85-95. https://doi.org/10. $1080 / 16138171.2020 .1765100$

Fan L (2020) The nature and judicial response of COVID-19 epidemic and administrative regulations as obstacles to the performance of house leasing contracts. Appl Law 5:37-47 ((in Chinese))

Feng Q (2003) On impossibility of performance. J Southwest Univ Pol Sci Law 6:112-115 ((in Chinese)) 
Ferrand A, Robinson L, Valette-Florence P (2010) The intention-torepurchase paradox: a case of the health and fitness industry. J Sp Manag 24:83-105

Garcia-Garcia B, James M, Koller D, Lindholm J, Mavromati D, Parrish R, Rodenberg R (2020) The impact of Covid-19 on sports: a mid-way assessment. Int Sp Law J 20:115-119. https://doi.org/ 10.1007/s40318-020-00174-8

Han S (2014) Research on several issues of change of circumstances. Chin Foreign Law 26(03):657-675 ((in Chinese))

Herresthal C, Xu D (2004) Study on the principle of changed circumstances. Peking Univ Law J 04:385-410 ((in Chinese))

Hutchison A (2010) The doctrine of frustration: a solution to the problem of changed circumstances in South African Contract Law? South Afr Law J 127:84-106

Jin S, He Y, Yang K, Gan Q, Wei W, Wang X, Meng C, Wang H (2021) The resumption of sports medicine during the COVID-19 postepidemic period: experiences from Wuhan, People's Republic of China. J Bone Joint Surg 103(1):10-14

Li K (2001) Some issues on principles and rules. Chin J Law 5:66-80 ((in Chinese))

Li J (2020) An analysis of force majeure and change of circumstances in cases of difficulties to perform contracts caused by epidemic. Appl Law 6:65-79 ((in Chinese))

Nauright J, Zipp S, Kim YH (2020a) The sports world in the era of COVID-19. Sp Soc 23(11):1703-1706

Nauright J, Zipp S, Kim YH (2020b) Tokyo Olympics on the happiness of O-MO-TE-NA-SHI workers in tourism: A consequence of COVID-19. Sustainability 12(19):8168. https://doi.org/10.3390/ su12198168

China News Network (2020a) The State General Administration of sports: The outbreak of sports industry caused great shock. http:// www.chinanews.com/ty/2020/02-26/9105574.shtml (in Chinese)

Nicola M, Alsafi Z, Sohrabi C, Kerwan A, Al-Jabir A, Iosifidis C, Agha M, Agha R (2020) The socio-economic implications of the coronavirus pandemic (COVID-19): a review. Int J Surg 78:185-193

Peng C (2014) From legal doctrine to rule of concrete case: The Civil Law application of Alexy's principle theory. Chin J Law 4:92-113 ((in Chinese))

Reade JJ, Singleton C (2020) Demand for public events in the COVID19 pandemic: a case study of European football. Eur Sp Manag Q. https://doi.org/10.1080/16184742.2020.1841261

Robinson L (2006) Customer expectations of sports organisations. Eur Sp Manag Q 6:67-84

Rösler H (2007) Hardship in German Codified Private Law - In comparative perspective to English, French and international contract law. Eur Rev Private Law 15:483

Rospigliosi EV, Rosenvald N, Maldonado MAT (2020) The COVID-19 pandemic, force majeure and changed contractual circumstances. Acta Bioethica 26(1):29-36

Sookaromdee P, Wiwanitkit V (2020) Sports stadium as spreading source of COVID-19. J Sp Med Phys Fit 60(5):806
State Council Information Office, People's Republic of China (2020) China's action against COVID-19 outbreak. White Paper. http:// www.scio.gov.cn/zfbps/32832/Document/1681801/1681801.htm (in Chinese)

Sun M (2004) Change of circumstances and contract theory. Law Press, Beijing (in Chinese)

Tan Q, Gong J (2020) Force majeure and civil liability in contracts and commercial rights: a discussion with Mr. Luo Wanli. Hebei Law Sci 20(3):125-129 ((in Chinese))

Timpka $\mathrm{T}$ (2020) sports in the tracks and fields of the corona virus: critical issues during the exit from lockdown. J Sci Med Sp 23(7):634-635

Wang L (2019) Discussion on several systems of change of circumstances: also commenting on Article 323 of the civil code contract section (Draft). Res Law and Bus 3:7-8 ((in Chinese))

Wang Y (2020) The COVID-19 pandemic, force majeure and change of circumstances. Law 3:36-38 ((in Chinese))

Wang H, Zhang W (2013) On the change of circumstances doctrine and its application in the field of comparative law research. Southeast Acad Res 3:163-167 ((in Chinese))

Wu X, Zhang J, Hou Z, Liu B (2020) Study on the impact and recovery strategy of the novel coronavirus on China's sports service industry. Sp Sci 41(3):17-24 ((in Chinese))

Yao H (2008) Changed circumstances revisited: from the perspective of the May 12 earthquake. Zhongzhou J 5:90-92 ((in Chinese))

Yao H, Que Z (2020) The intersection and boundary between changing situation and force majeure: taking the prevention and control measures of the new Pneumonia epidemic and post-epidemic reconstruction as an opportunity. J China Univ Political Sci Law 3:137-148 ((in Chinese))

Ye L (2007) On force majeure doctrine. Northern Law Science 5:36-44 ((in Chinese))

Yu Z (2017) Reflections on improving the principle of changed circumstances in China. J Xi an Jiaotong Univ Soc Sci 37(04):108-114 ((in Chinese))

Zhang L (2014) Why prioritizing mediation: from the perspective of dispute resolution approach. Stud Law Bus 31(04):118-126 ((in Chinese))

Zhang S, Ning Y (2019) On the right of re-negotiation in the principle of changed circumstances. Tsinghua Univ Law J 13(03):144-157 ((in Chinese))

Zhong B, Huang Z, Wang K (2020) Dilemma and response: focusing on the impact of COVID-19 epidemic on sports. J Sp Res 34(2):9-33 ((in Chinese))

Publisher's Note Springer Nature remains neutral with regard to jurisdictional claims in published maps and institutional affiliations. 